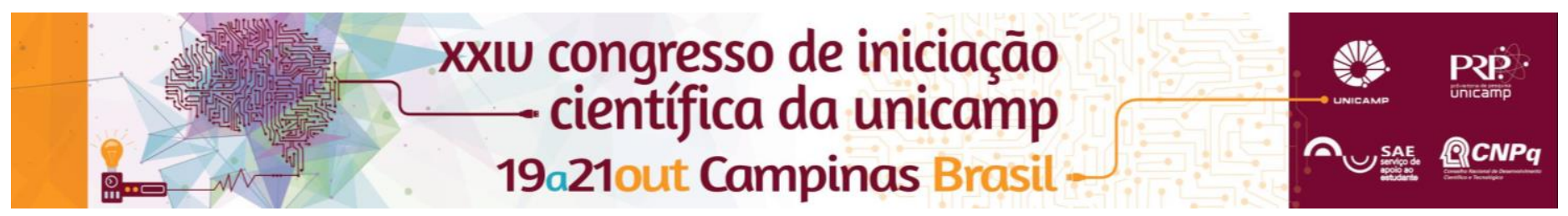

\title{
Estudo comparativo de extratos metanólicos de frutos de Mangostin e Pitaia com a Mangiferina e suas associações: atividade antioxidante e anticolinesterásica.
}

\section{Erica C. Fernandes ${ }^{\star}$, Wanda P. Almeida.}

\section{Resumo}

O projeto consiste em um estudo realizado com os frutos Mangostin (Garcinia mangostana) e Pitaia (Hylocereus sp.) afim de encontrar novas moléculas de importância farmacêutica para a Doença de Alzheimer. Realizou-se uma comparação com a mangiferina, composto natural bioativo que foi originalmente isolado das folhas de Manga (Mangifera indica L.), o qual possui atividade biológica bastante ampla. Sabe-se pela literatura que estes frutos são ricos em xantonas e que a mangiferina é composta pelo C-glicosídeo da xantona noratriol ${ }^{1}$, portanto, este estudo leva em consideração estas semelhanças estruturais para encontrar atividades farmacológicas em produtos naturais.

\section{Palavras-chave:}

Doença de Alzheimer, Pitaia, Mangostin.

\section{Introdução}

A Doença de Alzheimer (DA) é uma patologia multifatorial, apresentando alterações em diversos processos bioquímicos, tais como diminuição da transmissão colinérgica ${ }^{2}$ levando ao déficit da acetilcolina (ACh), neurotransmissor associado às funções cognitiva e motora, e alterações na transmissão glutamaérgica, resultando em excitotoxicidade e geração de espécies reativas de oxigênio (ROS) ${ }^{3}$. A contribuição de antioxidantes de origem natural para o retardo do avanço da doença vem sendo cada vez mais consolidada, deste modo, o projeto tem como objetivo encontrar novas fontes de tratamento para a doença, identificando propriedades de interesse nas frutas Pitaia e Mangostin e no composto mangiferina. Realizou-se o estudo tanto da atividade antioxidante quanto da anticolinesterásica - atividade de inibição da enzima que degrada a ACh. Além disso, estudou a atividade destes extratos associados entre si.

\section{Resultados e Discussão}

Os extratos metanólicos do pericarpo de Mangostin, da polpa e da casca da Pitaia foram obtidos com a maceração das frutas, adição de metanol, agitação por 1 hora à $60^{\circ} \mathrm{C}$ e posterior filtração. A mangiferina foi dissolvida em DMSO, para os testes.

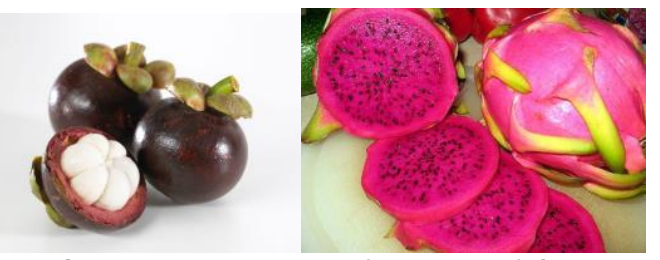

Figura 1. Garcinia mangostana (Mangostin) à esquerda e Hylocereus costaricensis (Pitaia de polpa vermelha) à direita.

Os extratos e a solução de mangiferina foram avaliados pelo método que emprega o 2,2-difenil-2-picrilhidrazil (DPPH) usando o procedimento descrito por Campos Júnior e colaboradores em uma adaptação de BrandWilliams e colaboradores, expondo o resultado em porcentagem de sequestro de radicais livres (\%SRL). E a medida da atividade da AChE foi realizada pelo método de Ellman, com resultado em porcentagem de inibição da acetilcolinesterase (\%AChE). A tabela a seguir demonstra os principais resultados obtidos.

Tabela 1. Resultados mais significativos dos testes realizados.

\begin{tabular}{|c|c|c|c|}
\hline Extrato & Concentração & $\%$ SRL & $\%$ AChE \\
\hline Mangiferina & $0,25 \mathrm{mM}$ & 81 & 84 \\
\hline $\begin{array}{c}\text { Pericarpo de } \\
\text { Mangostin }\end{array}$ & $5 \mathrm{mg} / \mathrm{mL}$ & 70 & 87 \\
\hline Polpa de Pitaia & $25 \mathrm{mg} / \mathrm{mL}$ & 91 & - \\
\hline Casca de Pitaia & $25 \mathrm{mg} / \mathrm{mL}$ & 64 & - \\
\hline $\begin{array}{c}\text { Associação } \\
\text { Mangostin e Polpa } \\
\text { de Pitaia }\end{array}$ & $\begin{array}{l}25 \mathrm{mg} / \mathrm{mL}: \\
37,5 \mathrm{mg} / \mathrm{mL}\end{array}$ & 87 & 72 \\
\hline $\begin{array}{c}\text { Associação } \\
\text { Mangostin e Casca } \\
\text { de Pitaia }\end{array}$ & $\begin{array}{c}25 \mathrm{mg} / \mathrm{mL}: \\
37,5 \mathrm{mg} / \mathrm{mL}\end{array}$ & - & 82 \\
\hline
\end{tabular}

\section{Conclusões}

Os resultados obtidos foram promissores. As atividades antioxidantes dos frutos foram comprovadas e o Mangostin demonstrou também possuir atividade anticolinesterásica, podendo ser um candidato para estudos no tratamento complementar da DA. Além disso, é interessante observar que as associações realizadas com os extratos demonstram diferentes atividades farmacológicas, o qual se deve à complexidade destes compostos naturais que poderão ser mais estudados futuramente.

\section{Agradecimentos}

CNPq - PIBIC pela bolsa de iniciação científica.

\footnotetext{
${ }^{1}$ Aritomi, M.; Kawasaki, T. A new xanthone C-glucoside, position isomer of mangiferin, from Anemarrhena asphodeloides Bunge. Tetrahedron Lett., 1969 $12,941-944$.

2 (a)Dong Z., Fu A.L., Prevention of age-related memory deficit in transgenic mice by human choline acetyltransferase, Eur. J. Pharmacol., 2012, 683, 174-178; (b) $\mathrm{Fu}$, A.L., Huang, S.J., Sun, M.J., Complementary remedy of aged-related learning and memory deficits via exogenous choline acetyltransferase, Biochem. Biophys. Res. Commun., 2005, 336, 268-273.

${ }^{3}$ Bonda, D. J.; Wang, X.; Perry, G.; Nunomura, A.; Tabaton, M.; Zhu, X.; Smith, M. A. Oxidative stress in Alzheimer disease: a possibility for prevention Neuropharmacology 2010, 59, 290-294.
} 